\title{
Análisis del color como connotador en la fotografía publicitaria
}

MHCJ no 5 | Año 2014

Artículo no3 (52)

Páginas 53 a 90

mhci.es
Félix Galindo Marín | fgalindo@ucam.edu Blas José Subiela Hernández | bsubiela@ucam.edu Manuel González-Sicilia Llamas | mgsicilia@ucam.edu
Palabras clave

Color; connotación; fotografía publicitaria; posicionamiento; retórica de la imagen; perfume.

Sumario

1. Introducción. 1.1. El sentido en la imagen publicitaria. 1.1.1. Denotación y connotación. 1.1.2. Connotación. 1.2. El color como connotador en la imagen. 1.2.1. Los significados del color.

2. Metodo. 2.1. Muestra. 2.2. Técnicas de trabajo. 2.2.1. Técnicas para la recogida de datos. 2.2.2. Técnicas para el análisis de datos.

3. Recogida de datos.

4. Análisis de resultados.

5. Conclusiones.

6. Referencias bibliográficas.

7. Notas.

\section{Resumen}

Partimos de la hipótesis de que el color es un elemento de la fotografía publicitaria capaz de añadir significados connotados. Consideramos que a lo largo de la historia y para la cultura occidental se han asociado una serie de significados de carácter simbólico y connotado a los diferentes tonos del color. Y la fotografía publicitaria los utiliza y los controla de forma que crea y refuerza el posicionamiento que se quiere dar al producto publicitado. Para probar nuestra hipótesis hemos desarrollado una herramienta de recogida y análisis de datos que hemos puesto a prueba con el estudio de tres fotografías publicitarias de perfumes de la compañía Lancôme: Trésor, Trésor in love y Trésor midnight rose. Se trata de tres posicionamientos muy claros, para públicos objetivos muy bien diferenciados. En los tres casos se detectan claves tonales y gamas de color muy concretas. Que enlazan con el universo simbólico con el que se rodea a cada uno de esos perfumes en las descripciones que la propia compañía realiza de cada uno de ellos en su sitio web (www.lancomespain.com).

\section{Forma de citar este artículo en las bibliografías}

Félix Galindo Marín, Blas José Subiela Hernández y Manuel González-Sicilia Llamas (2014): “Análisis del color como connotador en la fotografía publicitaria”, en Miguel Hernández Communication Journal, nº, páginas 53 a 90.

Universidad Miguel Hernández, UMH (Elche-Alicante). Recuperado el _ de de 20 de: http: $/ /$ mhcj.es $/$ index.php?journal $=$ mhcj\&page $=$ article\&op $=$ view\&path $\|=55$ 


\section{Analisys of color as connotator in advertising photography}

MHCJ no 5 | Year 2014

Paper no3 (52)

Pages 53 to 90

mhci.es
Félix Galindo Marín | fgalindo@ucam.edu Blas José Subiela Hernández | bsubiela@ucam.edu Manuel González-Sicilia Llamas | mgsicilia@ucam.edu

\section{Keywords}

Color; connotation; advertising;

photography; positioning; visual rhetoric; perfum.

\begin{abstract}
We hypothesized that color is an element of advertising photography able to add connoted meanings. We consider that throughout history and for Western culture there are some connoted and symbolic meanings associated to different color tones. And advertising photography uses and manages them so it creates and reinforces the positioning asigned to the advertised product. To test our hypothesis we developed a tool for collecting and analyzing data that we have tested with the study of three advertising photographs of perfume from Lancôme: Tresor, Tresor in love and Tresor midnight rose. These are three very clear positionings for very distinct target audiences. In all three cases are detected very specific tonal keys and color ranges. And they link to the symbolic universe which surrounds each of these fragrances in the descriptions that the own company makes on its website (www.lancomespain.com).
\end{abstract}

\section{How to cite this paper in bibliographies}

Félix Galindo Marín, Blas José Subiela Hernández y Manuel González-Sicilia Llamas (2014): “Análisis del color como connotador en la fotografía publicitaria”, en Miguel Hernández Communication Journal, n5, páginas 53 a 90. Universidad Miguel Hernández, UMH (Elche-Alicante). Recuperado el__ de___ de 20_ de: http: / / mhcj.es /index.php?journal=mhcj\&page $=$ article\&op $=$ view\&path $\% 5 \mathrm{~B} \% 5 \mathrm{D}=55$ 


\section{Introducción}

Esta investigación afronta el estudio del color en la fotografía como un elemento capaz de aportar significados connotados. Aunque existe abundante bibliografía al respecto, especialmente desde el campo de la semiótica, no hemos encontrado un modelo de análisis de contenido que sea objetivo y replicable y que permita detallar, de forma sistemática, la aportación de sentido que el color puede hacer a la imagen fotográfica. Por ello, consideramos que la principal aportación del presente trabajo se desarrolla en este sentido, ya que proponemos dicha herramienta y la testamos en tres imágenes fotográficas concretas.

Se trata, por lo tanto, de un trabajo que se enmarca en el ámbito de la comunicación y la semiótica, pero que también se relaciona con el campo de la educación, en lo que se refiere especialmente a competencia mediática. En España, este tipo de estudios están teniendo una gran aceptación en los últimos años y ello lo demuestran los trabajos realizados desde diversas instituciones2, que han detectado la necesidad de formar en competencias mediáticas a una sociedad que, si bien es consumidora casi compulsiva de lo audiovisual, adolece en la mayor parte de las ocasiones de la instrucción en lo que a lenguaje y expresión se refiere.

La fotografía no es ajena a esta realidad. Es un medio explotado por la mayor parte de los ciudadanos de las sociedades desarrolladas, sea en su forma convencional o mediante los nuevos dispositivos móviles. Todo el mundo es usuario, accede de forma inconsciente a la realidad documental de la fotografía, pero ¿todo el mundo expresa?

Entendemos que es necesario determinar, como productores de imágenes, y sobre todo como consumidores de fotografías, en qué forma significan estas, y cuáles son las partes que determinan este significado. "La condición puramente «denotativa» de la fotografía, la perfección y plenitud de su analogía, en resumen, su «objetividad» [...] es algo que corre el riesgo de ser mítico, pues de hecho existe una elevada probabilidad de que el mensaje fotográfico, o al menos el mensaje de prensa, esté también connotado" (Barthes, 2002: 15). Roland Barthes presenta así su sostenida defensa de la retórica de la imagen como respuesta a las cuestiones "¿cómo entra el sentido en la imagen?, ¿dónde acaba ese sentido? Y si acaba, ¿qué hay más allá?” (2002: 30).

Para resolver estos interrogantes de forma objetiva se hace necesario el desarrollo de herramientas que nos permitan observar de una forma lo más sistemática posible la aportación que cada uno de los elementos de la imagen fotográfica hacen al significado sugerido y percibido. Es relevante, en este sentido, el trabajo realizado desde hace más dos décadas por parte de Roberto Aparici y Agustín García Matilla, que -en colaboración con distintos autores- han desarrollado varias obras sobre el análisis y la representación de la realidad por medio de la imagen. También conocemos iniciativas como la planteada en 2004 por la Universidad Jaume I de Castellón, mediante la cual se realizó una propuesta de análisis 
de la imagen fotográfica, y cuyos resultados se materializaron en el I Congreso de teoría y técnica de los medios audiovisuales, el análisis de la imagen fotográfica.

Entre todas las aportaciones realizadas por esta iniciativa, una de las más significativas a nuestro juicio, es la considerable cantidad de literatura en torno al análisis de la imagen que generó. En todos estos estudios, el análisis se centra en la imagen artística, para lo que argumentan que "es el tipo de imágenes que da el juego suficiente para poder desarrollar un estudio analítico en profundidad"3.

En nuestro caso, y siguiendo a Barthes, nos fijaremos en la fotografía publicitaria como la imagen connotada por excelencia, puesto que persigue unos objetivos de comunicación y posicionamiento perfectamente definidos por el anunciante.

En concreto, centraremos la investigación en la publicidad de perfumes. Este sector nos permite conocer de una manera muy concreta la intencionalidad de la marca con respecto a cada producto, así como los atributos que pretende incorporar mediante la imagen y, en este caso, el color para lograr un posicionamiento determinado de cada producto.

Planteamos, en consecuencia, como hipótesis de nuestra investigación, que el color aporta significado a la imagen fotográfica publicitaria y que, por ello, se puede gestionar a través de determinadas variables controlables.

Para comprobar esa hipótesis, nos marcamos los siguientes objetivos en nuestro trabajo.

Definir los elementos que aportan significado a la imagen fotográfica publicitaria.

Definir el color como connotador en la fotografía publicitaria.

Elaborar una tabla que recoja la relación color - significado connotado.

Desarrollar un modelo de análisis que permita medir de forma objetiva la connotación del color en la fotografía publicitaria.

Probar nuestro modelo de análisis con tres casos concretos de publicidad de perfumes.

\subsection{El sentido en la imagen publicitaria}

La aproximación al sentido de la imagen ha sido estudiada por numerosos autores (Aparici, García Matilla y Valdivia, 1992, Aparici, García Matilla, Fernández Baena y Osuna Acedo, 2009; Barthes, 1993, 2000, 2002; Eco, 2000; Garrido Lora, 1995; Gubern; 1974; Joly, 2003; Marty \& Marty, 1995; Rodríguez García, 2008; Subiela, 2010; Susperregui, 2001; Zunzunegui, 1998; entre otros) quedando de manifiesto que los elementos de connotación de la imagen actúan como estímulo para la multiplicación del significado en una imagen. De entre estos elementos - propios de la realidad fotografiada unos, propios de la fotografía otrosdestacamos el color por su capacidad de connotación. 
La luz y el color han sido objeto de estudio desde diversos puntos de vista a lo largo de la historia. Desde Huygens (Traité de la lumière) en el siglo XVII hasta estudios más contemporáneos (Aumont, 1992; Goldstein, 2006; Hochberg, 1983; Küppers, 1995; Moreno \& Linares, 1999; Nó, 1996; Präkel, 2007).

Tras la revisión de la literatura que aborda los significados del color (Costa, 1992; Ferrer, 1999; Goethe; Heller, 2004; Moles \& Janiszewiski, 1992; Subiela, 2010; Zorrilla, 2002), nos ha parecido interesante recabar información acerca de los significados más comunes atribuidos a los distintos matices, y, de forma más concreta, estudiar el uso que se hacía de ellos en el medio publicitario.

\subsubsection{Denotación y connotación en la fotografía}

La denotación es el significado unívoco al que se refiere un signo, y es compartido por todos aquellos observadores partícipes de una cultura. "Podríamos denominarlo como el significado "objetivo", libre de interpretaciones más o menos personales, el que aparece reflejado en los diccionarios" (Subiela, 2010: 69).

Barthes (2002: 38-39), ya definía en este sentido la denotación. Pero más aún, y centrándose en la imagen fotográfica, hacía referencia a un mensaje sin código. Presuponiendo que cualquier persona, sólo por el hecho de pertenecer a una sociedad

"tiene un saber superior al saber antropológico y percibe algo más que lo puramente literal; por ser a la vez privativo y autosuficiente, es comprensible que el mensaje denotado pueda aparecer, desde una perspectiva estética, como un estado adámico de la imagen; el desembarazarse de forma utópica de sus connotaciones, la imagen se tornaría radicalmente objetiva, es decir, por fin inocente".

En comunicación publicitaria, la denotación hace referencia a aquellos aspectos que comunican atributos funcionales de la marca o del producto. Equivale al valor objetivo de los elementos que componen una pieza gráfica. Para Rodríguez García (2008)

"la denotación es el contenido puramente representativo de un signo, que lo hace útil para designar un determinado referente; y que está vinculada con lo que directamente expresa y refiere el signo. La connotación, en cambio, remite a otras ideas o evocaciones no presentes directamente en la denotación, son los significados añadidos. Es aquello que es sugerido sin ser referido".

Para Zunzunegui (1998: 60) la denotación se identifica con el hecho de que, según una correlación codificadora dada, a unos elementos dados del plano expresivo les corresponde de forma unívoca y directa una posición pertinente del contenido". Asimismo, "se hablará de connotación cuando el plano expresivo de una función semiótica se presente formado por 
otro sistema de significación (que incluye a su vez un plano expresivo y un plano de contenido)".

Marine Joly recuerda que "la imagen no es un signo [...] sino un texto, tejido mezclado de distintos tipos de signos, y que en efecto nos habla secretamente" (2003: 154). Y añadiremos, siguiendo a Barthes (2002: 41), en referencia a la fotografía publicitaria, que "ésta desempeña un papel particular que ya podemos empezar a precisar [...]: la imagen denotada vuelve natural al mensaje simbólico, vuelve inocente al artificio semántico, extremadamente denso (sobre todo en publicidad) de la connotación".

Esta coexistencia entre denotación y connotación es la que articula el discurso de la imagen publicitaria. Se resume en la lucha entre la imagen sincera y objetiva, la imagen verdad, frente a la imagen cultural y significada, marcada por el signo. Barthes (2002: 42), al referirse a la connotación matiza que, dado que los significados tienen una naturaleza semántica particular, nos encontramos con el problema de la falta de especialización del lenguaje con el que enfrentarnos al análisis y descodificación de la imagen. Esta aclaración no hace más que subrayar el modo con el que se debe abordar la lectura de una fotografía.

En el siguiente epígrafe desarrollaremos el sentido de la connotación y cuáles son los elementos que, dentro de la fotografía, establecen el sentido connotado de la imagen.

\subsubsection{Connotación en la fotografía publicitaria}

La denotación es la base sobre la que se sustenta una imagen. Sobre ésta se articulan una serie de elementos que son los que aportan el sentido completo a la misma. Roland Barthes, en su Retórica de la imagen, parte del concepto de mensaje lingüístico para argumentar su imagen denotada, sobre la que se construye la retórica de la imagen. La reconstrucción de los mecanismos en los que se agrupan los elementos que atribuyen el significado a una imagen "sólo será posible cuando se haya procedido a un inventario exhaustivo de los sistemas de connotación, no solamente de la imagen, sino que también de otras sustancias, ya que, si bien la connotación tiene significantes típicos de acuerdo con las sustancias utilizadas (imagen, palabra, objetos, conductas), tiene significados comunes" (2002: 44-45).

Raúl Eguizábal (2005: 88) justifica esta connotación en la fotografía en publicidad cuando sostiene la preexistencia del sentido en la fotografía. Su defensa de la preparación previa de la toma, en acuerdo con el trabajo previo de creación publicitaria, así lo confirma.

Román Gubern diferencia la fotografía como medio de representación de la realidad y la fotografía como medio de expresión, aunque considera que nunca se puede dar uno u otro modelo de forma pura: "Aún en la más banal utilización de la fotografía como medio reproductor penetra cierto coeficiente de creatividad por parte del fotógrafo, mediante la selección espacial del encuadre o a través de alguno de los otros medios formativos enunciados" (1974:54). 
Esta concepción del hecho fotográfico concuerda con el concepto de persuasores ocultos al que hace referencia Minor White en su texto Equivalencia: tendencia perpetua (Fontcuberta, 2003:250), y por el que afirma que "si la publicidad puede utilizar el efecto subliminal del diseño en fotografía para vender un producto, el fotógrafo con talento puede utilizar el mismo aspecto del diseño para más iluminados propósitos".

En su texto La imagen, Roland Barthes (2002:11-28) presenta lo que denomina los procedimientos de la connotación. Con ellos trata de hacer referencia a los mecanismos de los cuales se sirve la imagen fotográfica. Estos son:

Trucaje. Para el autor "ningún otro tratamiento permite a la connotación enmascararse con más perfección tras la «objetividad» de la denotación”.

Pose. La pose del sujeto fotografiado atribuye acciones estereotipadas que confieren un sentido añadido a la imagen. Como amplía Barthes "la pose no es en lo específico un procedimiento fotográfico, pero no queda más remedio que hablar de ella, ya que su efecto proviene del principio analógico en que se funda la fotografía".

Objetos. Presentados bien como lo que podríamos definir como inductores habituales de asociaciones de ideas (gafas-estudioso) o bien como auténticos símbolos (un cuervo negro en una alegoría gótica). Estos objetos contienen un elevado potencial de significado.

Fotogenia. Serían aquellas técnicas que permiten la imagen «embellecida» (sublimada). Nos referimos a las técnicas de iluminación, impresión y reproducción, lo que hoy denominamos como técnica fotográfica. En este punto Barthes anima a la elaboración de un catálogo de aquellas técnicas "aunque sólo fuera en la medida en que a cada una de ellas le corresponde un significado de connotación lo suficientemente estable como para incorporarse a un léxico cultural de los efectos técnicos. Invita también a la distinción entre los efectos estéticos y significantes, matizando entre aquellos que están al servicio del sentido y los que están en el arte.

Esteticismo. En referencia, sobre todo, a la analogía pintura-fotografía, y la lucha que ésta, entonces, mantenía por su independencia. Más concretamente, al uso que en ocasiones puede realizar la fotografía de técnicas puramente pictóricas, como el empaste de colores.

Sintaxis. Entendida como la lectura discursiva de objetos o signos dentro de un encuadre, y más aún, con carácter "suprasegmental”, es decir, por encadenamiento de imágenes.

Dentro de esta clasificación, el color estaría considerado como uno de esos objetos-signos a los que hacemos referencia, y su comportamiento estará supeditado tanto a la sintaxis como a los efectos del esteticismo. 
El autor francés (Barthes, 2002:45) continúa definiendo estos significantes de connotación, específicos para cada disciplina:

"llamaremos connotadores a estos significantes y retórica al conjunto de los connotadores", a la vez que destaca que "no todos los elementos de la lexía pueden transformarse en connotadores, en el discurso siempre permanece un cierto grado de denotación sin el cual, precisamente, el discurso dejaría de ser posible".

Rodríguez García (2008) defiende que "las connotaciones que encierra una imagen son la forma más efectiva de persuasión publicitaria. La fuerza persuasiva de la connotación reside en su sutileza". Por su parte, Joly (2003:153) se muestra de acuerdo con Barthes cuando éste reconoce en el signo icónico

"una dimensión fuertemente connotativa. Sin embargo, vimos que el signo icónico no era el único que entraba en la composición de la imagen, que había que considerar también la fuerza semiótica de los signos plásticos, así como su interacción con los signos lingüísticos y el contexto institucional y comunicacional de aparición del mensaje visual. Nos haría falta entonces ampliar la proposición de Barthes y reconocer que todo en la imagen, cada elemento del mensaje visual, puede ser connotativo y que este proceso no le está reservado únicamente al signo icónico.”

El signo es, pues, un estímulo sustituto del estímulo directo del objeto, y su efectividad consiste en producir la misma reacción que la presencia del objeto. Según González Solas (2001:1) "actuaría como el reflejo condicionado: la presencia de un estímulo secundario, e incluso arbitrario, produciría los mismos efectos que la presencia del estímulo real”.

Centrándonos en los connotadores a los que hace referencia Barthes, encontramos una primera y completa descripción realizada por Carlos Abreu (1999a, 1999b y 2000). Esta clasificación de connotadores, realizada en torno a la imagen informativa -si bien generalizable a toda fotografía con intencionalidad comunicativa, también la publicitariasurge del concepto "opinión fotográfica" en alusión a la funcionalidad de los mismos. Distingue también entre la "opinión implícita, en la que el grado de subjetividad es inconsciente y/o producto de la aplicación de una línea informativa" y la "opinión explícita, como aquélla en la que el emisor emite sus juicios y pareceres directamente, sin subterfugios” (Abreu, 1999a). Continúa señalando como punto de partida los elementos profotográficos y fotográficos, es decir "aquellos valores connotativos que de por sí poseen culturalmente los componentes de la escena fotográfica, y los elementos propiamente fotográficos que determinan la escena final".

Obviamente, la realidad que capta la cámara -elementos profotográficos- está plena de significaciones. Este referente encuentra en numerosas ocasiones otro sentido más allá de lo 
que se observa, y que puede ser captado por quien realiza la toma y por el observador de la imagen. Abreu señala que este hecho puede darse con la apariencia, elementos de la naturaleza, culturales y lingüísticos, entre otros.

Los elementos fotográficos que pueden conferir connotaciones a la imagen son, para Abreu, "entre otros, la angulación, el encuadre, la composición, la iluminación y las sombras; el contraste, el lente usado (sic), el grano y el color" (Abreu, 1999b).

Eguizábal (2001:76) realiza una clasificación cronológica de los elementos técnico-expresivos -los atribuibles únicamente a la fotografía como expresión, la fotogenia y el trucaje de Barthes- y los agrupa según su orden de intervención en las fases del proceso fotográfico: fase de disparo, procesado del negativo y procesado del papel (procesos válidos también en la actual fotografía digital).

Blas Subiela (2010:201) habla de los connotadores como "una serie de variables que pueden dotar a la imagen de intencionalidad". En su caso, realiza una distinción entre los connotadores técnicos, dentro de los cuales estarían el encuadre y la iluminación; y los connotadores compositivos, entre los que incluye la pose, la escenificación y la sintaxis.

En el siguiente epígrafe centraremos nuestro estudio en uno de los connotadores citados por los distintos autores, el color. Como fuente única de la fotografía, la luz y su comportamiento se presentan fundamentales para entender a un invitado que llegó a esta forma de expresión para quedarse. El color supuso una nueva forma de contar en fotografía que, aun en coexistencia con el blanco y negro, muestra continuamente sus propios medios para aportar significado a la imagen.

\subsection{El color como connotador en la imagen}

Para Joan Costa (1992:133 y ss.) el color puede tener tres usos diferentes en la imagen publicitaria: denotado, connotado y simbólico. Aunque en este trabajo nos centraremos en el uso connotado, resumiremos brevemente los otros dos usos asignados al color en la imagen publicitaria por parte de este autor.

Según Costa, el uso denotado del color es el presente en imágenes realistas, procedentes de la fotografía o de la ilustración. El color denotado es aquel que refleja la realidad y se convierte en un complemento del discurso estético. En cuanto al uso simbólico, es aquel que se ha extendido tanto en toda la sociedad que se ha convertido en una norma. En este sentido, consideramos más acertado denominar este uso como estandarizado, ya que hace referencia a colores que se han estandarizado como normas (por ejemplo, los colores del semáforo).

No obstante, el uso sobre el que centramos nuestros esfuerzos en este trabajo, como ya se ha señalado, es el connotado, que podemos definir como el color cuyo significado procede de 
una visión subjetiva, aunque dicha visión se pueda hacer extensible a grupos más o menos amplios y homogeneos de población.

El color connotado es independiente de las formas y de las texturas de la imagen. Este uso del color posee la capacidad de generar estados de ánimo, de transmitir sensaciones por medio de una percepción sensitiva, espontánea y compartida. "Es una propiedad del color ambiente (más que de la forma) que se encuentra [...] en todas las manifestaciones gráficas coloreadas". (Costa, 1992:138) Según estas palabras, el uso del color connotado crea atmósferas que pueden transmitir estados de ánimo.

En su libro Teoría de los colores, Goethe fue el primero que de un modo sistemático abordara los efectos psicológicos que producen los colores en el ser humano. El color "produce sobre el sentido de la vista, al que pertenece y, por conducto de él, sobre el alma humana $[\ldots]$ un efecto específico [...] siempre definido y significativo, que se vincula estrechamente con la esfera moral" (Goethe: VI, 758-777).

Goethe estableció dos grupos de colores agrupando "del lado del más (que) son el amarillo, el amarillo rojizo (anaranjado) y el rojo amarillento (minio, bermejo). Estos colores vuelven al hombre vivaz, activo y dinámico" y por otro, los "correspondientes al lado del menos (que) son el azul, el azul bermejo y el rojo azulado. Estos colores suscitan en el alma inquietud, emoción y anhelo".

Apuntamos aquí también la aportación de Vasili Kandinski (2010:70) que en su obra "De lo espiritual en el arte" establece que "las secciones que llaman inmediatamente la atención son: 1. Calor y frío del color." y "2. Claridad y oscuridad del color". Kandinski insiste en que la cualidad de calor o frío en un color está determinada "en líneas generales" por su tendencia hacia el amarillo o el azul.

\subsubsection{Los significados del color}

El estudio realizado por Eva Heller en su obra Psicología del color (2004) nos muestra cómo afectan los colores a los sentimientos y a la razón. Esta obra identifica un total de trece colores que denomina como independientes e insustituibles (Heller, 2004:117):

"Los teóricos de los colores distinguen entre colores primarios -rojo, amarillo y azul-, colores secundarios -verde, anaranjado y violeta- y mezclas subordinadas, como rosa, gris o marrón. También discuten sobre si el blanco y el negro son verdaderos colores, y generalmente ignoran el dorado y el plateado, aunque, en un sentido psicológico, cada uno de estos trece colores es un color independiente que no puede sustituirse por ningún otro, y todos presentan la misma importancia." 
Tomando como base estos trece colores o matices, hemos realizado una revisión de las obras más relevantes sobre los significados psicológicos del color (Goethe: VI, Costa, 1992, Ferrer, 1999 y Heller, 2004) y hemos ordenado nuestros resultados en trece tablas sintéticas. En ellas, para cada color, se muestran los siguientes campos:

1. Combinaciones. Para reflejar las posibilidades de utilización del matiz primario con uno secundario enunciadas por los autores, y mostrar las connotaciones resultantes.

2. Identificaciones. Equivalencias semánticas asociadas a un determinado matiz.

3. Capacidades. También podríamos definirlo como la posibilidad de un determinado matiz de conferir propiedades directas al sujeto de la enunciación.

4. Connotaciones positivas. Significados que confieren atributos positivos al sujeto del enunciado.

5. Connotaciones negativas. Significados que confieren atributos negativos al sujeto del enunciado.

Cuadro 1: Connotaciones del color

\begin{tabular}{|c|c|c|c|c|c|}
\hline Color & $\begin{array}{l}\text { Variaciones y } \\
\text { combinaciones }\end{array}$ & Identificaciones & Capacidades & $\begin{array}{l}\text { Connotaciones } \\
\text { positivas }\end{array}$ & $\begin{array}{l}\text { Connotaciones } \\
\text { negativas }\end{array}$ \\
\hline Azul & & $\begin{array}{l}\text { Femenino } \\
\text { Espiritual }\end{array}$ & $\begin{array}{l}\text { Atrae } \\
\text { Predispone } \\
\text { favorece }\end{array}$ & $\begin{array}{l}\text { Simpatico } \\
\text { Armonioso } \\
\text { Fiel } \\
\text { Atractivo }\end{array}$ & $\begin{array}{l}\text { Distante } \\
\text { Ciego } \\
\text { Triste } \\
\text { Deprimido }\end{array}$ \\
\hline & Negro & & Atrae & & \\
\hline & Blanco & Científico & Concentra & $\begin{array}{l}\text { Limpio } \\
\text { Seguro }\end{array}$ & $\begin{array}{l}\text { Vacío } \\
\text { Indiferente }\end{array}$ \\
\hline
\end{tabular}

\begin{tabular}{|l|l|l|l|l|l|}
\hline Color & $\begin{array}{l}\text { Variaciones y } \\
\text { combinaciones }\end{array}$ & Identificaciones & Capacidades & $\begin{array}{l}\text { Connotaciones } \\
\text { positivas }\end{array}$ & $\begin{array}{l}\text { Connotaciones } \\
\text { negativas }\end{array}$ \\
\hline Rojo & & $\begin{array}{l}\text { Vital } \\
\text { Aoasionado } \\
\text { Fuerte, Brutal } \\
\text { Problemático (en } \\
\text { economía) } \\
\text { Político }\end{array}$ & Enamora & $\begin{array}{l}\text { Virilidad } \\
\text { Energía } \\
\text { Exaltación }\end{array}$ & $\begin{array}{l}\text { Agresividad } \\
\text { Problemas } \\
\text { económicos }\end{array}$ \\
& & & & & \\
\hline & Negro & Transmite peligro & & \\
\hline
\end{tabular}

\begin{tabular}{|l|l|l|l|l|l|}
\hline Color & $\begin{array}{l}\text { Variaciones y } \\
\text { combinaciones }\end{array}$ & Identificaciones & Capacidades & $\begin{array}{l}\text { Connotaciones } \\
\text { positivas }\end{array}$ & $\begin{array}{l}\text { Connotaciones } \\
\text { negativas }\end{array}$ \\
\hline
\end{tabular}




\begin{tabular}{|l|l|l|l|l|l|}
\hline Amarillo & Intenso & Recrea la vista & Alegría & Violencia \\
& & Alegra el ánimo & Claridad & Estridencia \\
& & Ilumina & Gratitud & Inestabilidad \\
& & Se expande & Confortabilidad & Contradicción \\
& & Transmite & Ardorosidad & \\
\hline
\end{tabular}

\begin{tabular}{|l|l|l|l|l|l|}
\hline Color & $\begin{array}{l}\text { Variaciones y } \\
\text { combinaciones }\end{array}$ & Identificaciones & Capacidades & $\begin{array}{l}\text { Connotaciones } \\
\text { positivas }\end{array}$ & $\begin{array}{l}\text { Connotaciones } \\
\text { negativas }\end{array}$ \\
\hline Verde & & Ecología & & Satisfacción visual & Venenoso \\
& & Fertilidad & Simplicidad & Putrefacto \\
& & Esperanza & & & Inhumano \\
& & & & & Perversión \\
\end{tabular}

\begin{tabular}{|l|l|l|l|l|l|}
\hline Color & $\begin{array}{l}\text { Variaciones y } \\
\text { combinaciones }\end{array}$ & Identificaciones & Capacidades & $\begin{array}{l}\text { Connotaciones } \\
\text { positivas }\end{array}$ & $\begin{array}{l}\text { Connotaciones } \\
\text { negativas }\end{array}$ \\
\hline Negro & & Juventud & Nobleza & Elegancia \\
& & Moda & & Credibilidad \\
& & Silencio & & Mala suerte \\
& Misterio & Moche & & & Crash económico \\
& & & & & \\
\hline & Los del lado del & & Ganan energía & & \\
\hline
\end{tabular}

\begin{tabular}{|l|l|l|l|l|l|}
\hline Color & $\begin{array}{l}\text { Variaciones y } \\
\text { combinaciones }\end{array}$ & Identificaciones & Capacidades & $\begin{array}{l}\text { Connotaciones } \\
\text { positivas }\end{array}$ & $\begin{array}{l}\text { Connotaciones } \\
\text { negativas }\end{array}$ \\
\hline Blanco & & Fantasmas & Luminosidad & Paz & Muerte \\
& & Desconocido & Vacío & Pureza & Miedo \\
& Teología & Infinito & Inocencia & Derrota \\
& & & Confiere positivismo & Perfección & \\
& & & & El Bien & Vida \\
\hline
\end{tabular}

\begin{tabular}{|l|l|l|l|l|l|}
\hline Color & $\begin{array}{l}\text { Variaciones y } \\
\text { combinaciones }\end{array}$ & Identificaciones & Capacidades & $\begin{array}{l}\text { Connotaciones } \\
\text { positivas }\end{array}$ & $\begin{array}{l}\text { Connotaciones } \\
\text { negativas }\end{array}$ \\
\hline Naranja & & & Gran Visibilidad & & \\
\hline & Amarillo Rojizo & Fuego Superior & Potente y Magnífico & Acogedor & \\
\hline
\end{tabular}




\begin{tabular}{|l|l|l|l|l|l|}
\hline & & & Calor & & \\
\hline & Rojo Amarillento & & & & Violencia \\
& & & & & Insoportable \\
\hline
\end{tabular}

\begin{tabular}{|l|l|l|l|l|l|}
\hline Color & $\begin{array}{l}\text { Variaciones y } \\
\text { combinaciones }\end{array}$ & Identificaciones & Capacidades & $\begin{array}{l}\text { Connotaciones } \\
\text { positivas }\end{array}$ & $\begin{array}{l}\text { Connotaciones } \\
\text { negativas }\end{array}$ \\
\hline Violeta & & $\begin{array}{l}\text { Masculinidad y } \\
\text { feminidad }\end{array}$ & $\begin{array}{l}\text { Contradictorio } \\
\text { Oposición }\end{array}$ & $\begin{array}{l}\text { Templanza } \\
\text { Lucidez }\end{array}$ & Sensualidad \\
pecaminosa \\
\end{tabular}

\begin{tabular}{|l|l|l|l|l|l|}
\hline Color & $\begin{array}{l}\text { Variaciones y } \\
\text { combinaciones }\end{array}$ & Identificaciones & Capacidades & $\begin{array}{l}\text { Connotaciones } \\
\text { positivas }\end{array}$ & $\begin{array}{l}\text { Connotaciones } \\
\text { negativas }\end{array}$ \\
\hline Rosa & & Chicas jóvenes & Optimismo & Pudor & Inmoralidad \\
& & Feminidad & Pequeño & Suavidad \\
& & Ternura erótica & & Pasión & Mal \\
& & Desnudo & & Bien & \\
\hline & & & & & \\
\hline
\end{tabular}

\begin{tabular}{|c|c|c|c|c|c|}
\hline Color & $\begin{array}{l}\text { Variaciones y } \\
\text { combinaciones }\end{array}$ & Identificaciones & Capacidades & $\begin{array}{l}\text { Connotaciones } \\
\text { positivas }\end{array}$ & $\begin{array}{l}\text { Connotaciones } \\
\text { negativas }\end{array}$ \\
\hline \multirow[t]{2}{*}{ Oro } & & $\begin{array}{l}\text { Dinero } \\
\text { Fama }\end{array}$ & & Belleza & $\begin{array}{l}\text { Ofuscamiento } \\
\text { Falsedad }\end{array}$ \\
\hline & Amarillo & & & & $\begin{array}{l}\text { Falso } \\
\text { Presuntuoso }\end{array}$ \\
\hline
\end{tabular}

\begin{tabular}{|l|l|l|l|l|l|}
\hline Color & $\begin{array}{l}\text { Variaciones y } \\
\text { combinaciones }\end{array}$ & Identificaciones & Capacidades & $\begin{array}{l}\text { Connotaciones } \\
\text { positivas }\end{array}$ & $\begin{array}{l}\text { Connotaciones } \\
\text { negativas }\end{array}$ \\
\hline Plata & & Tecnología & Introvertido & Esterilidad & Consolación \\
\hline
\end{tabular}




\begin{tabular}{|l|l|l|l|l|l|}
\hline & & $\begin{array}{l}\text { Modernidad } \\
\text { Investigación }\end{array}$ & & Limpieza & Frío \\
\hline & Blanco & Cortesía & & & Distante \\
\hline
\end{tabular}

\begin{tabular}{|l|l|l|l|l|l|}
\hline Color & $\begin{array}{l}\text { Variaciones y } \\
\text { combinaciones }\end{array}$ & Identificaciones & Capacidades & $\begin{array}{l}\text { Connotaciones } \\
\text { positivas }\end{array}$ & $\begin{array}{l}\text { Connotaciones } \\
\text { negativas }\end{array}$ \\
\hline Marrón & & Vestimenta & Efecto agradable & Equilibrio & Sucio \\
Otoño & Gravedad & Desvirtuado \\
& & Moda & & Severidad & Feo \\
& Naturaleza & & Nobleza & Vejez \\
& Masculino & & & Problemas \\
& Pobreza & & & \\
& Siervos & & & \\
& Criados & & & \\
\hline
\end{tabular}

\begin{tabular}{|l|l|l|l|l|l|}
\hline Color & $\begin{array}{l}\text { Variaciones y } \\
\text { combinaciones }\end{array}$ & Identificaciones & Capacidades & $\begin{array}{l}\text { Connotaciones } \\
\text { positivas }\end{array}$ & $\begin{array}{l}\text { Connotaciones } \\
\text { negativas }\end{array}$ \\
\hline Gris & & Neutro & Difumina & Experiencia & Tristeza \\
& & Pasivo & Falta de energía & Respetabilidad \\
Sin valor & Sabiduria & Melancolía \\
Languidez \\
Vejez \\
Antigüedad \\
Crueldad \\
\end{tabular}

Fuente: elaboración propia

\section{Métodología}

Como se ha señalado al comienzo del texto, nuestro marco práctico se desarrolla en torno al análisis de la imagen publicitaria de perfumes. Sin embargo, las herramientas y la metodología que ahora presentamos se proponen como válidas para cualquier sector publicitario. 


\subsection{Muestra}

La selección de perfumes para delimitar nuestra muestra no es fruto del azar. El perfume es uno de los productos más intangible del mercado. La atribución de valores, así como la recreación de atmósferas es un recurso necesario para el posicionamiento de este tipo de productos.

Según la Asociación Nacional de Perfumería y Cosmética, "es destacable que el mercado europeo de perfumería y cosmética, es el más importante del mundo, ya que en la Unión Europea supone unos 70.300 millones de $€ /$ año (cinco billones de unidades de productos consumidos por más de 350 millones de europeos)". Las cifras del negocio de la perfumería son acordes a las de su gasto publicitario.

Dentro del sector de la perfumería, nos hemos centrado en la marca Lancôme. Perteneciente a L'Oreal desde 1964, de la que es una de sus marcas del sector lujo. El grupo, con 27 marcas internacionales y casi 70.000 empleados, tiene presencia en 130 países.

Lancôme cuenta con una gama de perfumería de 14 fragancias femeninas y dos masculinas. Para realizar nuestro estudio hemos seleccionado una marca emblemática de la firma, Trésor, puesto que, además de la original, cuenta con dos fragancias que, si bien mantienen la misma denominación, están destinadas a públicos distintos. Hablamos de Trésor in Love y Trésor Midnight Rose. Estos perfumes constituyen una expansión de la línea original y nos van a permitir realizar un estudio segmentado de un mismo producto.

Los tres casos estudiados pertenecen a la campaña internacional que la marca ha empleado en 2012. Se corresponden con las composiciones en su versión horizontal, para homogeneizar la muestra. Las piezas empleadas son las siguientes:

Cuadro 2: Muestra. Campañas gráficas Trésor, Trésor in Love, Trésor Midnight Rose

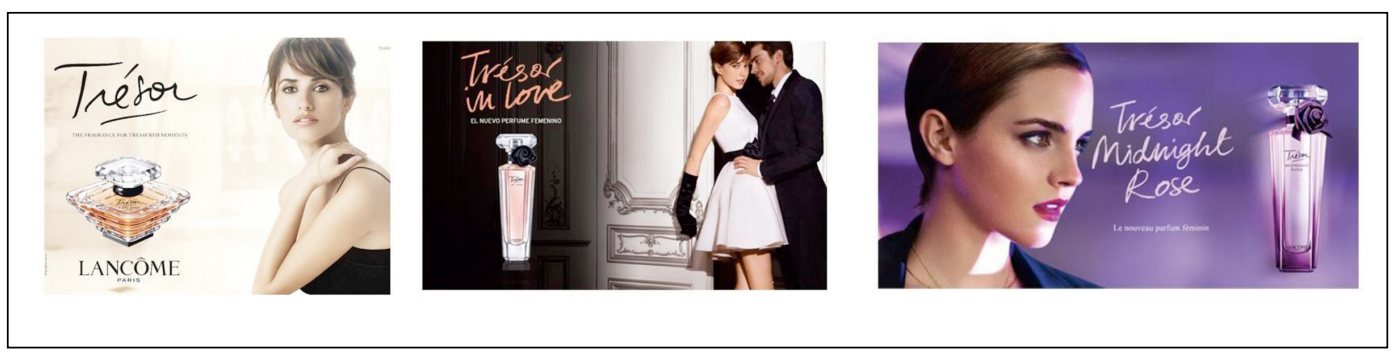

Fuente: Lancôme

\subsection{Técnicas de trabajo}

Para el desarrollo del marco práctico de esta investigación se ha recurrido a técnicas descriptivas. En primer lugar, proponemos una herramienta que permite recoger datos sobre el color de la imagen publicitaria de forma sistemática y objetiva. Una vez obtenidos esos 
datos, se enfrentan, por una parte a los resultados obtenidos en el marco teórico sobre los significados connotados del color y, por otra parte, a los objetivos del anunciante con respecto al posicionamiento del producto. De este modo se puede comprobar el nivel de coherencia o divergencia entre las decisiones de los directores de arte y fotógrafos y los responsables de elaborar el posicionamiento del producto anunciado.

\subsubsection{Técnicas para la recogida de datos}

\subsubsection{Recogida de datos de la imagen: color dominante, colores frecuentes y color principal.}

En primer lugar se trata de afrontar una recogida de datos lo más sistemática posible. Para ello, hemos elaborado una ficha para cada imagen analizada en la que se incluirán el color dominante y los diez colores más frecuentes de la composición. Estos datos se objetivan y sistematizan por medio de la herramienta informática Whatsitscolor4, que permite obtener, mediante un algoritmo, el color dominante de la imagen, definido como la media de los colores más frecuentes, el color complementario dominante, el número de colores visualmente únicos y, de éstos, los diez más frecuentes.

A partir del resultado de este análisis informático, hemos reflejado en nuestra ficha cada uno de los colores con su denominación RGB (valores de síntesis aditiva del color, red, blue, green) y HSB (modo básico de color compuesto por Hue, Saturation, Brightness). Éste último dato nos proporciona información en cuanto a valor de matiz $(\mathrm{H})$, medido en grados $\left.{ }^{\circ}\right)$ correspondientes al círculo cromático para otorgar un color único, brillo (B), representado en un porcentaje $(\%)$ en el que un valor bajo representa proximidad al negro y saturación (S), también medido en porcentaje (\%), y representando un valor bajo de éste mayor proximidad al gris.

Los valores de saturación y brillo nos permitirán emitir juicios de valor en cuanto a estas magnitudes, y serán tenidos en cuenta como bajos cuando se encuentren en un rango de entre $0 \%-33,3 \%$, medios cuando estén entre $33,4 \%-66,6 \%$ y altos cuando se encuentre entre $66,7 \%$ y $100 \%$.

Para aumentar la objetividad en la definición del matiz, hemos empleado la herramienta Kuler5 de Adobe con la finalidad de visualizar de una forma clara la ubicación de los valores HSB dentro del círculo cromático y así poder clasificarlos con mayor precisión.

Somos conscientes de que el color dominante puede suponer una aportación parcial a la hora de determinar cuál es el color más importante de una fotografía. Aspectos como el peso visual, el equilibrio, la proporción o las áreas positivas y negativas, pueden hacer que el color dominante de una composición no sea, sin embargo, el color más importante de la fotografía. 
Por ello, hemos considerado pertinente añadir en esta fase de recogida de datos el color propio del producto como el color principal de la composición publicitaria. No podemos pasar por alto que el color, como atributo de los productos comerciales, es un valor que, si bien es tangible, aporta una carga de connotación muy importante.

\section{Cuadro 3: Ficha de recogida de datos}

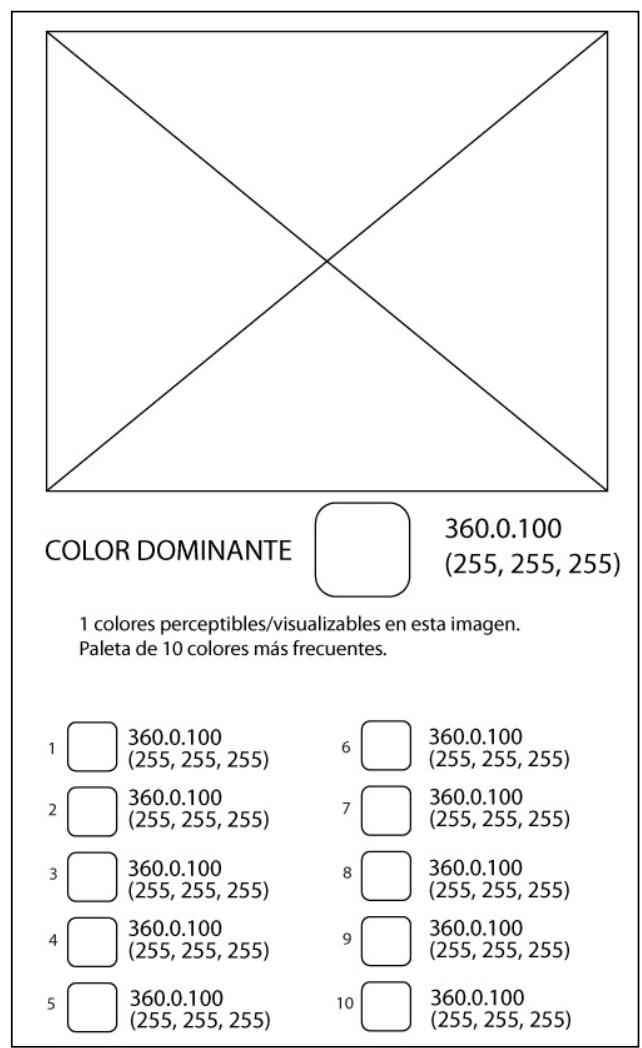

Fuente: elaboración propia

\subsubsection{Recogida de datos del producto: posicionamiento sobre valores intangibles}

Es imprescindible para nuestra investigación conocer también la intencionalidad del anunciante respecto al posicionamiento que desea de su producto. Dicha intencionalidad es expresada en la descripción que el anunciante realiza de cada producto a través de su web oficial. En el caso concreto de nuestra muestra objeto de estudio, Lancôme presenta cada uno de sus perfumes con un texto en el que se encuentran numerosos adjetivos que realizan una minuciosa descripción de la fragancia y se establecen como una carta de intenciones del fabricante frente al posicionamiento buscado. Para nuestro análisis, extraemos las ideas principales de cada uno de esos textos, esquematizándolas, seleccionando los núcleos verbales, los adjetivos y adverbios que hacen clara referencia a los atributos perseguidos por el anunciante. Ese listado, nos permite establecer un punto de partida para el análisis. 
Obviando el anclaje del texto, comparamos esta intencionalidad con la connotación obtenida con los colores que se han empleado en la elaboración de las gráficas de los tres perfumes. Excluiremos en el análisis las connotaciones negativas atribuidas a los colores puesto que, aun siendo conscientes de que, salvo en una construcción errónea del mensaje o en una atribución intencionada de valores negativos, la voluntad de la marca es asignar significados entendidos como positivos. Este hecho también se sostiene observando los textos de presentación de cada uno de los perfumes ofrecidos por Lancôme.

\subsubsection{Técnicas para el análisis de datos}

Una vez obtenidos todos los datos, se vuelcan sobre una tabla en la que se organizan, en columnas, del siguiente modo:

En primer lugar, se introducen los colores extraídos de la imagen publicitaria como dominante, frecuentes y principal, obtenidos según la metodología definida en el epígrafe

\subsection{1.}

En segundo lugar, se presentan, para cada uno de los colores de la primera columna, los significados simbólicos que se les han asignado a lo largo del marco teórico y que han sido sintetizados en la tabla 1.

Por último, se colocan los atributos con los que el anunciante busca que el producto sea asociado, los cuales han sido extraídos de las descripciones realizadas en su propia web oficial.

El proceso de construcción de esta ficha ha pasado por diferentes fases: revisión de la literatura existente sobre el tema, observación de otras fichas elaboradas en diferentes investigaciones referidas al análisis de la imagen fotográfica y una revisión de la ficha por un grupo de expertos -Universidad de Murcia, Universidad de Valladolid, Universidad Católica San Antonio de Murcia-, a través de un cuestionario contestado por correo electrónico.

Las aportaciones del grupo de expertos hicieron referencia al uso del modo HSB frente al RGB en el análisis de la imagen, así como al diseño de la tabla, sugiriendo, entre otras aportaciones, la inclusión de una muestra en la misma para facilitar su lectura. Estas apreciaciones fueron tenidas en cuenta en el rediseño de nuestra herramienta. 
Cuadro 4: Ficha de análisis

FICHA DE ANÁLISIS DEL COLOR COMO CONNOTADOR EN LA IMAGEN FOTOGRÁFICA PUBLICITARIA

IMAGEN ANALIZADA

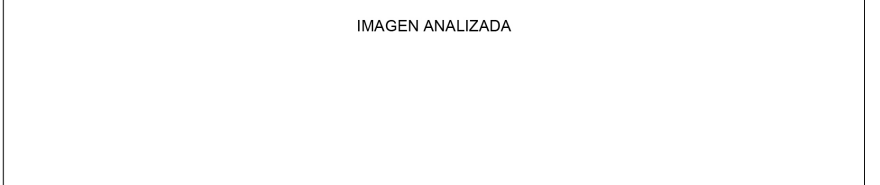

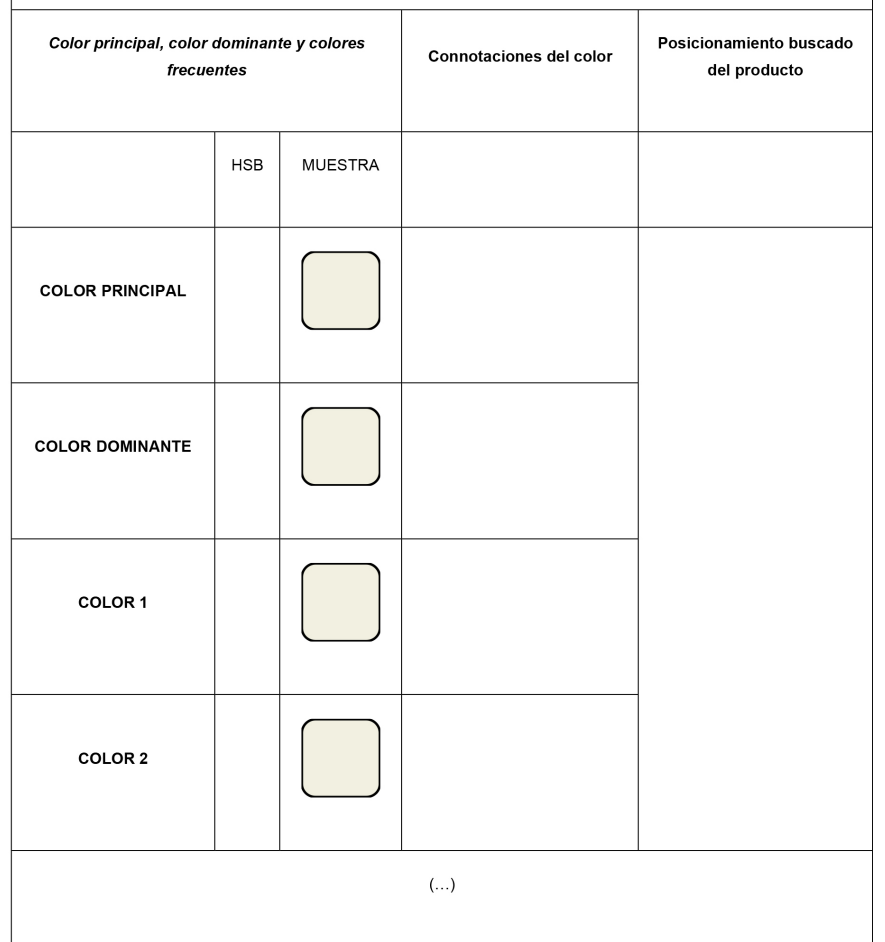

Fuente: elaboración propia 


\section{Recogida de datos}

Cuadro 4: Ficha de análisis caso 1. Trésor

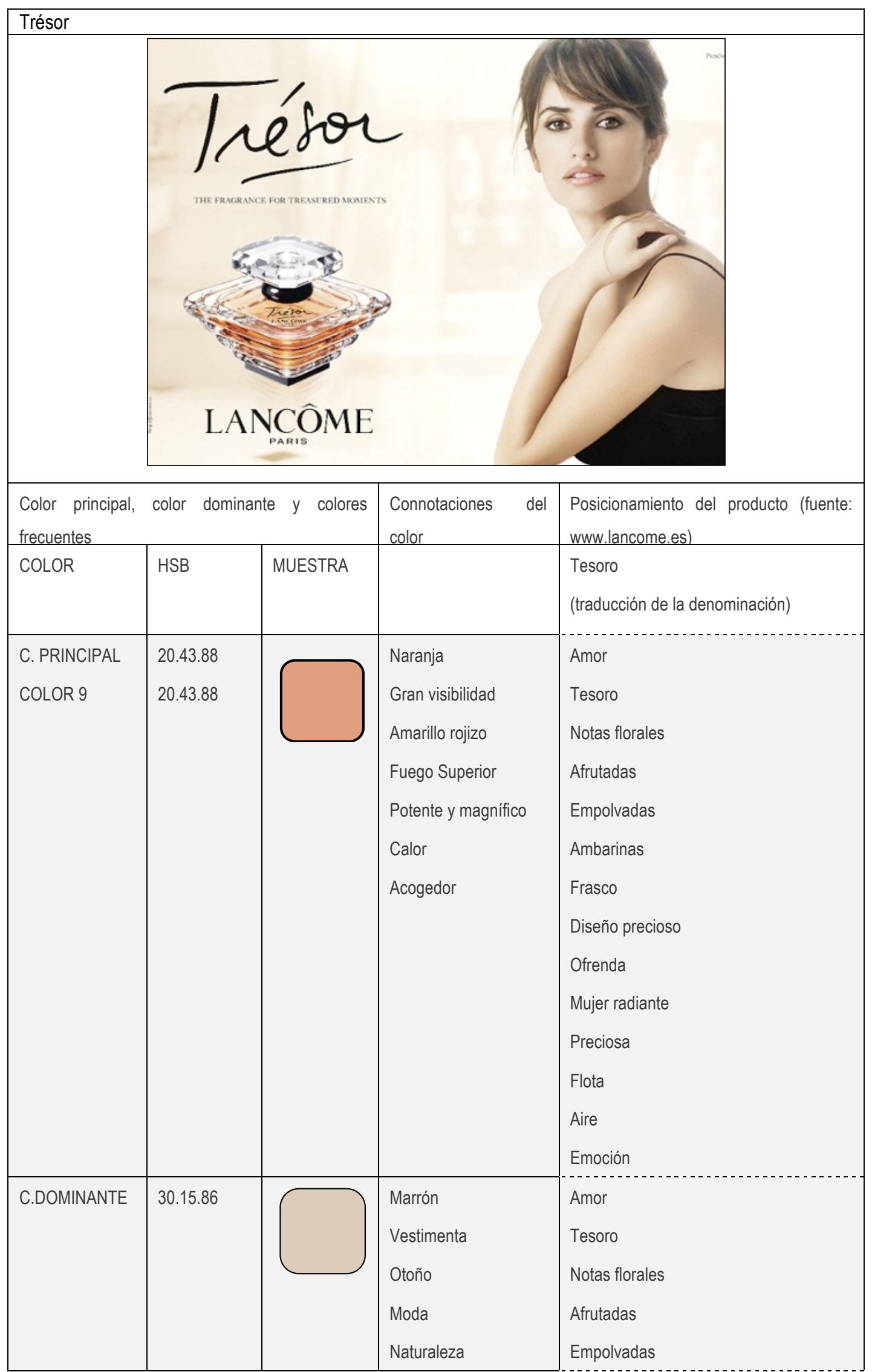




\begin{tabular}{|c|c|c|c|}
\hline & & $\begin{array}{l}\text { Masculino } \\
\text { Pobreza } \\
\text { Siervos } \\
\text { Criados } \\
\text { Mendigos } \\
\text { Efecto agradable } \\
\text { Equilibrio } \\
\text { Gravedad } \\
\text { Severidad } \\
\text { Confortable } \\
\text { Nobleza }\end{array}$ & $\begin{array}{l}\text { Ambarinas } \\
\text { Frasco } \\
\text { Diseño precioso } \\
\text { Ofrenda } \\
\text { Mujer radiante } \\
\text { Preciosa } \\
\text { Flota } \\
\text { Aire } \\
\text { Emoción }\end{array}$ \\
\hline $\begin{array}{l}\text { COLOR } 1 \\
\text { COLOR } 4\end{array}$ & $\begin{array}{l}60.7 .94 \\
60.14 .88\end{array}$ & $\begin{array}{l}\text { Amarillo } \\
\text { Intenso } \\
\text { Recrea la vista } \\
\text { Alegra el ánimo } \\
\text { Luminosidad } \\
\text { Expansivo } \\
\text { Transmisor } \\
\text { emergencias de } \\
\text { Alegría } \\
\text { Claridad } \\
\text { Gratitud } \\
\text { Confortabilidad } \\
\text { Ardiente }\end{array}$ & $\begin{array}{l}\text { Amor } \\
\text { Tesoro } \\
\text { Notas florales } \\
\text { Afrutadas } \\
\text { Empolvadas } \\
\text { Ambarinas } \\
\text { Frasco } \\
\text { Diseño precioso } \\
\text { Ofrenda } \\
\text { Mujer radiante } \\
\text { Preciosa } \\
\text { Flota } \\
\text { Aire } \\
\text { Emoción }\end{array}$ \\
\hline COLOR 2 & 0.7 .94 & $\begin{array}{l}\text { Rosa } \\
\text { Chicas jóvenes } \\
\text { Feminidad } \\
\text { Ternura erótica } \\
\text { Desnudo } \\
\text { Optimismo } \\
\text { Pequeño } \\
\text { Pudor } \\
\text { Inocencia } \\
\text { Suavidad } \\
\text { Pasión } \\
\text { Bien }\end{array}$ & $\begin{array}{l}\text { Amor } \\
\text { Tesoro } \\
\text { Notas florales } \\
\text { Afrutadas } \\
\text { Empolvadas } \\
\text { Ambarinas } \\
\text { Frasco } \\
\text { Diseño precioso } \\
\text { Ofrenda } \\
\text { Mujer radiante } \\
\text { Preciosa } \\
\text { Flota } \\
\text { Aire }\end{array}$ \\
\hline
\end{tabular}




\begin{tabular}{|c|c|c|c|}
\hline & & & Emoción \\
\hline COLOR 3 & 0.0 .94 & $\begin{array}{l}\text { Blanco } \\
\text { Fantasmas } \\
\text { Desconocido } \\
\text { Teología } \\
\text { Luminosidad } \\
\text { Vacio } \\
\text { Infinito } \\
\text { Confiere positivismo } \\
\text { Paz } \\
\text { Pureza } \\
\text { Inocencia } \\
\text { Perfección } \\
\text { El bien } \\
\text { Vida }\end{array}$ & $\begin{array}{l}\text { Amor } \\
\text { Tesoro } \\
\text { Notas florales } \\
\text { Afrutadas } \\
\text { Empolvadas } \\
\text { Ambarinas } \\
\text { Frasco } \\
\text { Diseño precioso } \\
\text { Ofrenda } \\
\text { Mujer radiante } \\
\text { Preciosa } \\
\text { Flota } \\
\text { Aire } \\
\text { Emoción }\end{array}$ \\
\hline $\begin{array}{l}\text { COLOR } 5 \\
\text { COLOR } 6 \\
\text { COLOR } 7\end{array}$ & $\begin{array}{l}40.40 .94 \\
30.29 .88 \\
291.160 .198\end{array}$ & $\begin{array}{l}\text { Marrón } \\
\text { Vestimenta } \\
\text { Otoño } \\
\text { Moda } \\
\text { Naturaleza } \\
\text { Masculino } \\
\text { Pobreza } \\
\text { Siervos } \\
\text { Criados } \\
\text { Mendigos } \\
\text { Efecto agradable } \\
\text { Equilibrio } \\
\text { Gravedad } \\
\text { Severidad } \\
\text { Confortable } \\
\text { Nobleza }\end{array}$ & $\begin{array}{l}\text { Amor } \\
\text { Tesoro } \\
\text { Notas florales } \\
\text { Afrutadas } \\
\text { Empolvadas } \\
\text { Ambarinas } \\
\text { Frasco } \\
\text { Diseño precioso } \\
\text { Ofrenda } \\
\text { Mujer radiante } \\
\text { Preciosa } \\
\text { Flota } \\
\text { Aire } \\
\text { Emoción }\end{array}$ \\
\hline
\end{tabular}




\begin{tabular}{|c|c|c|c|}
\hline COLOR 8 & 0.0 .0 & $\begin{array}{l}\text { Negro } \\
\text { Juventud } \\
\text { Moda } \\
\text { Silencio } \\
\text { Misterio } \\
\text { Noche } \\
\text { Nobleza } \\
\text { Elegancia } \\
\text { Credibilidad }\end{array}$ & $\begin{array}{l}\text { Amor } \\
\text { Tesoro } \\
\text { Notas florales } \\
\text { Afrutadas } \\
\text { Empolvadas } \\
\text { Ambarinas } \\
\text { Frasco } \\
\text { Diseño precioso } \\
\text { Ofrenda } \\
\text { Mujer radiante } \\
\text { Preciosa } \\
\text { Flota } \\
\text { Aire } \\
\text { Emoción }\end{array}$ \\
\hline COLOR 10 & 0.0 .88 & $\begin{array}{l}\text { Gris } \\
\text { Neutro } \\
\text { Pasivo } \\
\text { Sin valor } \\
\text { Difumina } \\
\text { Falta de energía } \\
\text { Experiencia } \\
\text { Respetabilidad } \\
\text { Sabiduría }\end{array}$ & $\begin{array}{l}\text { Amor } \\
\text { Tesoro } \\
\text { Notas florales } \\
\text { Afrutadas } \\
\text { Empolvadas } \\
\text { Ambarinas } \\
\text { Frasco } \\
\text { Diseño precioso } \\
\text { Ofrenda } \\
\text { Mujer radiante } \\
\text { Preciosa } \\
\text { Flota } \\
\text { Aire } \\
\text { Emoción }\end{array}$ \\
\hline
\end{tabular}

Fuente: elaboración propia 
Cuadro 5: Ficha de análisis caso 2. Trésor in Love

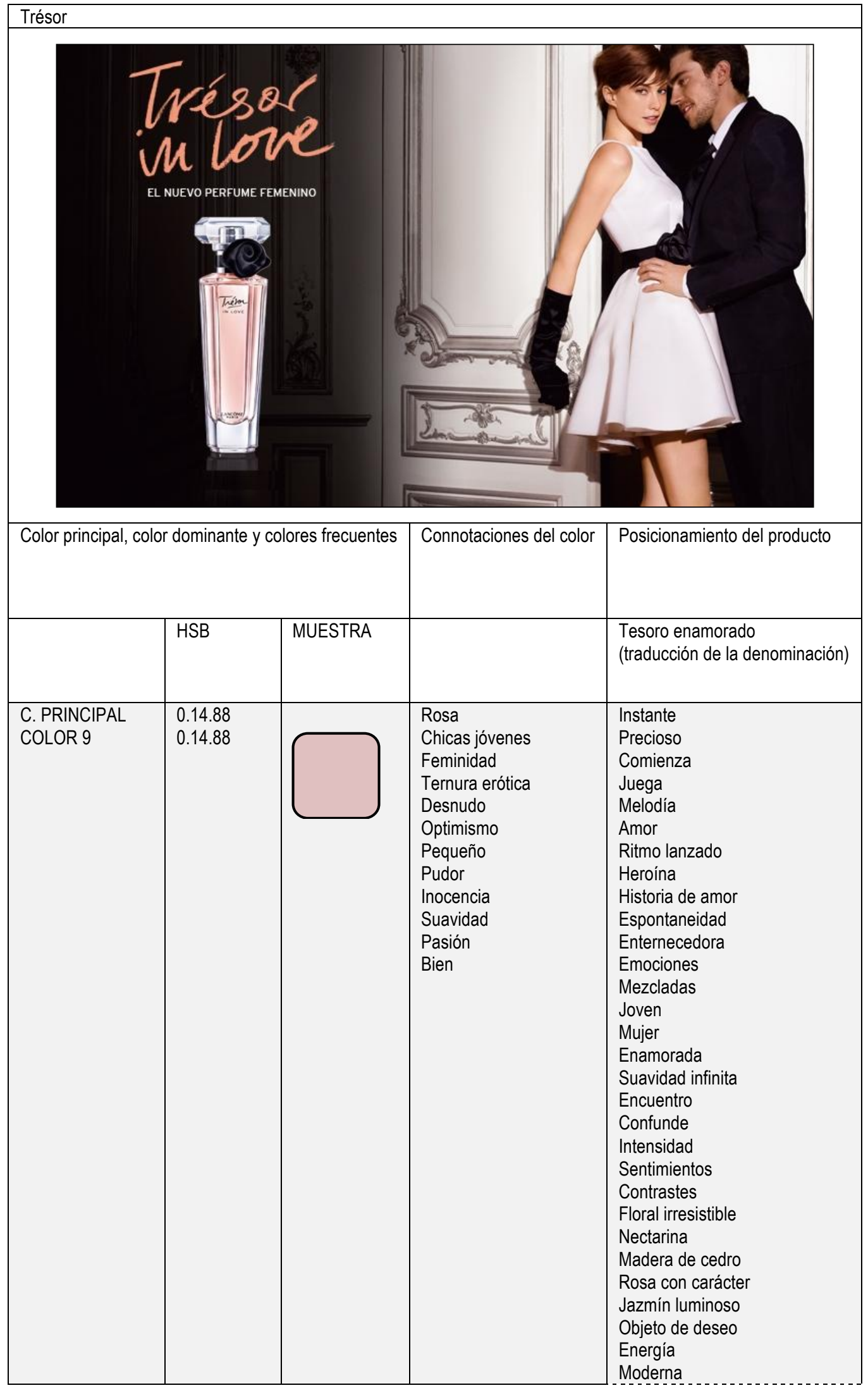




\begin{tabular}{|c|c|c|c|}
\hline $\begin{array}{l}\text { C. DOMINANTE } \\
\text { COLOR } 6 \\
\text { COLOR } 8 \\
\text { COLOR } 10\end{array}$ & $\begin{array}{l}5.13 .40 \\
0.0 .75 \\
0.0 .38 \\
0.0 .63\end{array}$ & $\begin{array}{l}\text { Gris } \\
\text { Neutro } \\
\text { Pasivo } \\
\text { Sin valor } \\
\text { Difumina } \\
\text { Falta de energía } \\
\text { Experiencia } \\
\text { Respetabilidad } \\
\text { Sabiduría }\end{array}$ & $\begin{array}{l}\text { Instante } \\
\text { Precioso } \\
\text { Comienza } \\
\text { Juega } \\
\text { Melodía } \\
\text { Amor } \\
\text { Ritmo lanzado } \\
\text { Heroína } \\
\text { Historia de amor } \\
\text { Espontaneidad } \\
\text { Enternecedora } \\
\text { Emociones } \\
\text { Mezcladas } \\
\text { Joven } \\
\text { Mujer } \\
\text { Enamorada } \\
\text { Suavidad infinita } \\
\text { Encuentro } \\
\text { Confunde } \\
\text { Intensidad } \\
\text { Sentimientos } \\
\text { Contrastes } \\
\text { Floral irresistible } \\
\text { Nectarina } \\
\text { Madera de cedro } \\
\text { Rosa con carácter } \\
\text { Jazmín luminoso } \\
\text { Objeto de deseo } \\
\text { Energía } \\
\text { Moderna } \\
\text { Mo-....... }\end{array}$ \\
\hline $\begin{array}{l}\text { COLOR } 1 \\
\text { COLOR } 3 \\
\text { COLOR } 4 \\
\text { COLOR } 5 \\
\text { COLOR } 7\end{array}$ & $\begin{array}{l}0.0 .0 \\
0.0 .13 \\
0.100 .13 \\
300.100 .13 \\
0.0 .25\end{array}$ & $\begin{array}{l}\text { Negro } \\
\text { Juventud } \\
\text { Moda } \\
\text { Silencio } \\
\text { Misterio } \\
\text { Noche } \\
\text { Nobleza } \\
\text { Elegancia } \\
\text { Credibilidad }\end{array}$ & $\begin{array}{l}\text { Instante } \\
\text { Precioso } \\
\text { Comienza } \\
\text { Juega } \\
\text { Melodía } \\
\text { Amor } \\
\text { Ritmo lanzado } \\
\text { Heroína } \\
\text { Historia de amor } \\
\text { Espontaneidad } \\
\text { Enternecedora } \\
\text { Emociones } \\
\text { Mezcladas } \\
\text { Joven } \\
\text { Mujer } \\
\text { Enamorada } \\
\text { Suavidad infinita } \\
\text { Encuentro } \\
\text { Confunde } \\
\text { Intensidad } \\
\text { Sentimientos } \\
\text { Contrastes } \\
\text { Floral irresistible } \\
\text { Nectarina } \\
\text { Madera de cedro } \\
\text { Rosa con carácter } \\
\text { Jazmín luminoso } \\
\text { Objeto de deseo } \\
\text { Energía } \\
\text { Moderna }\end{array}$ \\
\hline COLOR 2 & 0.0 .88 & $\begin{array}{l}\text { Blanco } \\
\text { Fantasmas } \\
\text { Desconocido } \\
\text { Teología } \\
\text { Luminosidad } \\
\text { Vacío } \\
\text { Infinito } \\
\end{array}$ & $\begin{array}{l}\text { Instante } \\
\text { Precioso } \\
\text { Comienza } \\
\text { Juega } \\
\text { Melodía } \\
\text { Amor } \\
\text { Ritmo lanzado }\end{array}$ \\
\hline
\end{tabular}




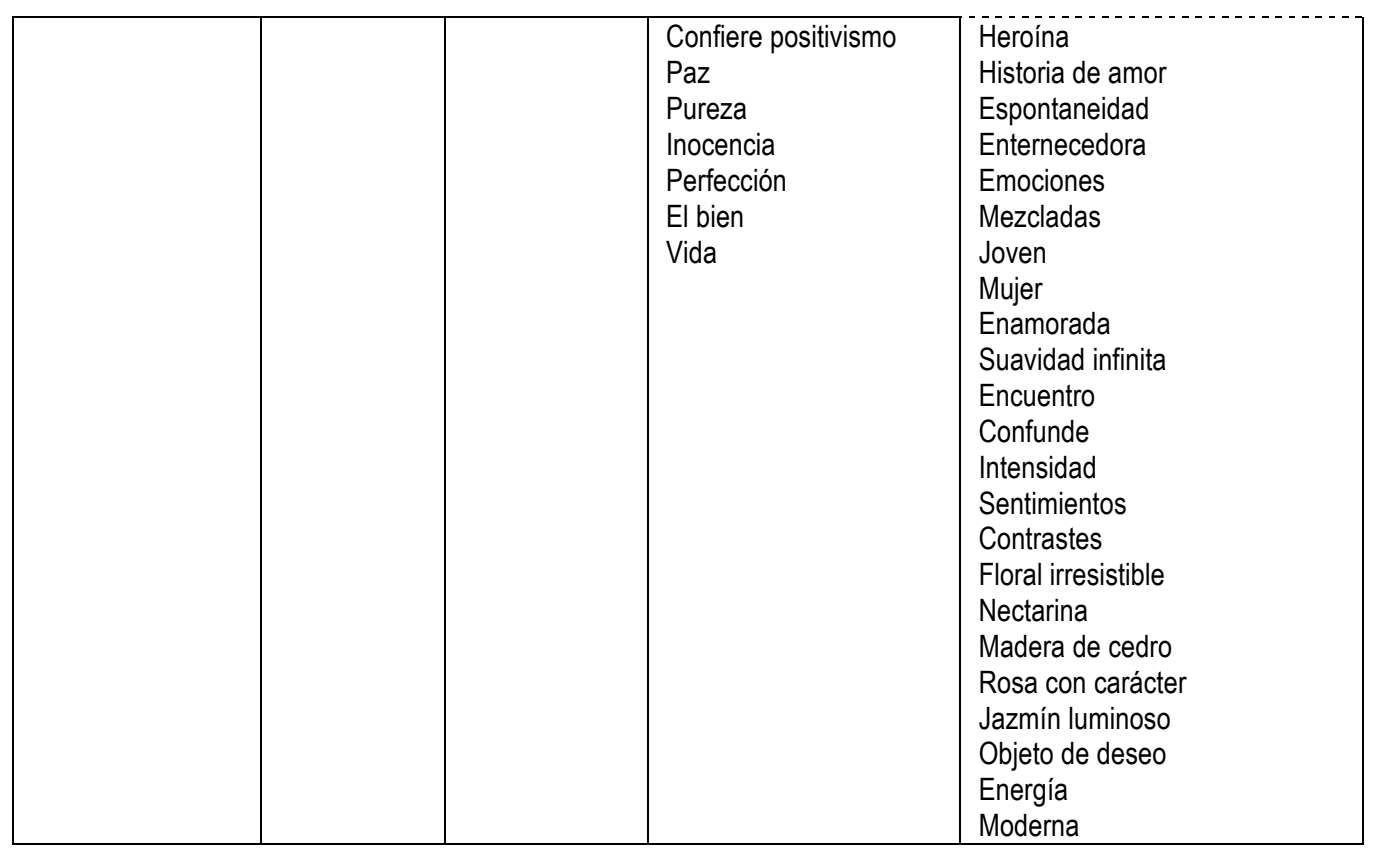

Fuente: elaboración propia 
Cuadro 6: Ficha de análisis caso 3. Trésor Midnight Rose

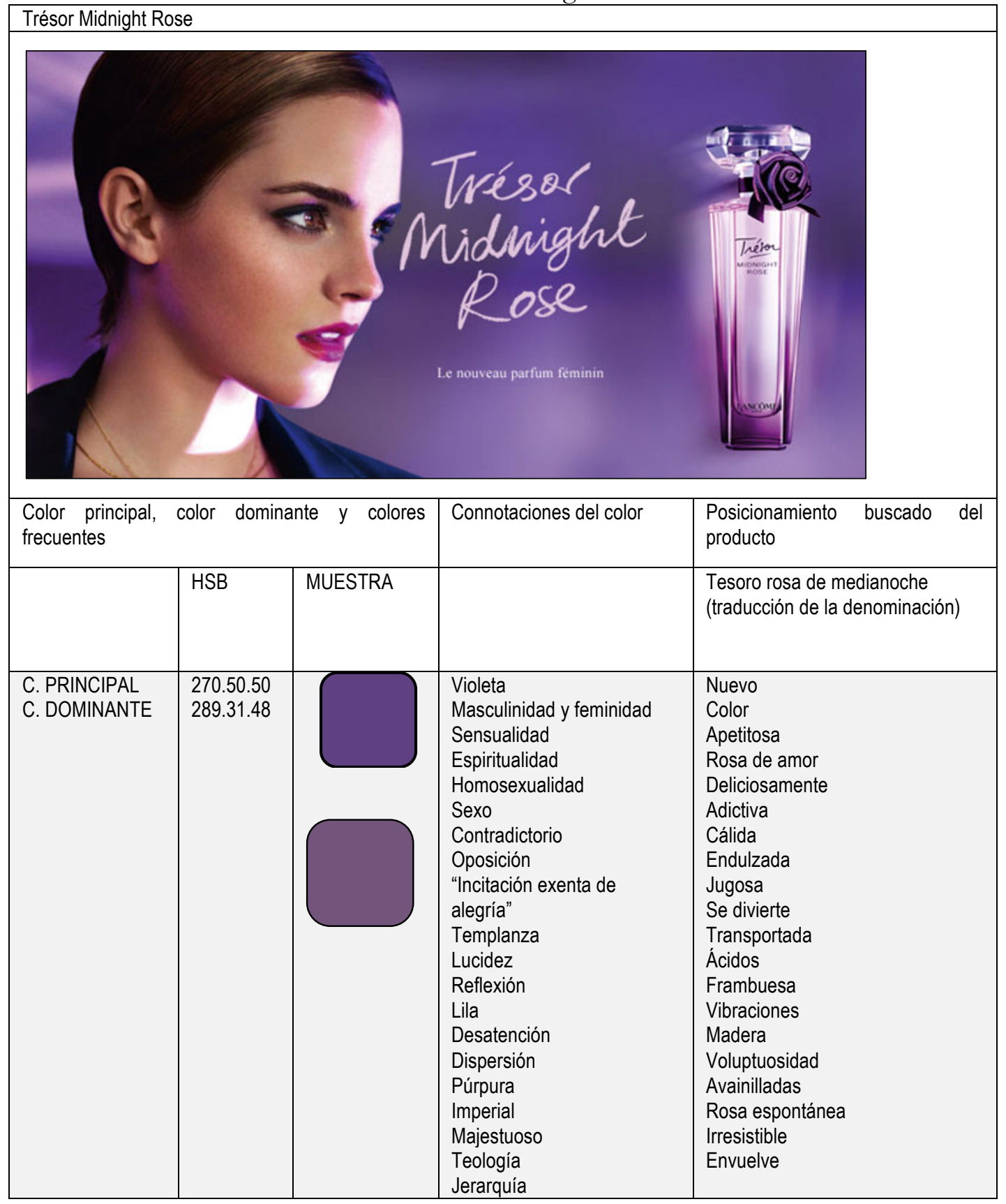




\begin{tabular}{|c|c|c|c|}
\hline $\begin{array}{l}\text { COLOR } 1 \\
\text { COLOR } 2 \\
\text { COLOR } 4 \\
\text { COLOR } 5 \\
\text { COLOR } 7\end{array}$ & $\begin{array}{l}270.50 .50 \\
270.40 .63 \\
260.60 .63 \\
270.33 .75 \\
270.67 .38\end{array}$ & $\begin{array}{l}\text { Violeta } \\
\text { Masculinidad y feminidad } \\
\text { Sensualidad } \\
\text { Espiritualidad } \\
\text { Homosexualidad } \\
\text { Sexo } \\
\text { Contradictorio } \\
\text { Oposición } \\
\text { "Incitación exenta de } \\
\text { alegría" } \\
\text { Templanza } \\
\text { Lucidez } \\
\text { Reflexión } \\
\text { Lila } \\
\text { Desatención } \\
\text { Dispersión } \\
\text { Púrpura } \\
\text { Imperial } \\
\text { Majestuoso } \\
\text { Teología } \\
\text { Jerarquía }\end{array}$ & $\begin{array}{l}\text { Nuevo } \\
\text { Color } \\
\text { Apetitosa } \\
\text { Rosa de amor } \\
\text { Deliciosamente } \\
\text { Adictiva } \\
\text { Cálida } \\
\text { Endulzada } \\
\text { Jugosa } \\
\text { Se divierte } \\
\text { Transportada } \\
\text { Ácidos } \\
\text { Frambuesa } \\
\text { Vibraciones } \\
\text { Madera } \\
\text { Voluptuosidad } \\
\text { Avainilladas } \\
\text { Rosa espontánea } \\
\text { Irresistible } \\
\text { Envuelve }\end{array}$ \\
\hline COLOR 3 & 0.0 .0 & $\begin{array}{l}\text { Negro } \\
\text { Juventud } \\
\text { Moda } \\
\text { Silencio } \\
\text { Misterio } \\
\text { Noche } \\
\text { Nobleza } \\
\text { Elegancia } \\
\text { Credibilidad }\end{array}$ & $\begin{array}{l}\text { Nuevo } \\
\text { Color } \\
\text { Apetitosa } \\
\text { Rosa de amor } \\
\text { Deliciosamente } \\
\text { Adictiva } \\
\text { Cálida } \\
\text { Endulzada } \\
\text { Jugosa } \\
\text { Se divierte } \\
\text { Transportada } \\
\text { Ácidos } \\
\text { Frambuesa } \\
\text { Vibraciones } \\
\text { Madera } \\
\text { Voluptuosidad } \\
\text { Avainilladas } \\
\text { Rosa espontánea } \\
\text { Irresistible } \\
\text { Envuelve }\end{array}$ \\
\hline $\begin{array}{l}\text { COLOR } 6 \\
\text { COLOR } 8\end{array}$ & $\begin{array}{l}240.50 .50 \\
240.33 .38\end{array}$ & $\begin{array}{l}\text { Azul } \\
\text { Femenino } \\
\text { Virtudes espirituales } \\
\text { Atracción } \\
\text { Predisposición favorable } \\
\text { Simpatía } \\
\text { Armonía } \\
\text { Fidelidad } \\
\text { Capacidad } \\
\text { Atracción }\end{array}$ & $\begin{array}{l}\text { Nuevo } \\
\text { Color } \\
\text { Apetitosa } \\
\text { Rosa de amor } \\
\text { Deliciosamente } \\
\text { Adictiva } \\
\text { Cálida } \\
\text { Endulzada } \\
\text { Jugosa } \\
\text { Se divierte } \\
\text { Transportada } \\
\text { Ácidos } \\
\text { Frambuesa } \\
\text { Vibraciones } \\
\text { Madera } \\
\text { Voluptuosidad } \\
\text { Avainilladas } \\
\text { Rosa espontánea } \\
\text { Irresistible } \\
\text { Envuelve }\end{array}$ \\
\hline
\end{tabular}




\begin{tabular}{|c|c|c|c|}
\hline COLOR 9 & 0.50 .50 & $\begin{array}{l}\text { Rojo } \\
\text { Vitalidad } \\
\text { Pasión } \\
\text { Fuerza Brutal } \\
\text { Política } \\
\text { Enamora } \\
\text { Virilidad } \\
\text { Energía } \\
\text { Exaltante }\end{array}$ & $\begin{array}{l}\text { Nuevo } \\
\text { Color } \\
\text { Apetitosa } \\
\text { Rosa de amor } \\
\text { Deliciosamente } \\
\text { Adictiva } \\
\text { Cálida } \\
\text { Endulzada } \\
\text { Jugosa } \\
\text { Se divierte } \\
\text { Transportada } \\
\text { Ácidos } \\
\text { Frambuesa } \\
\text { Vibraciones } \\
\text { Madera } \\
\text { Voluptuosidad } \\
\text { Avainilladas } \\
\text { Rosa espontánea } \\
\text { Irresistible } \\
\text { Envuelve }\end{array}$ \\
\hline COLOR 10 & 20.50 .75 & $\begin{array}{l}\text { Marrón } \\
\text { Vestimenta } \\
\text { Otoño } \\
\text { Moda } \\
\text { Naturaleza } \\
\text { Masculino } \\
\text { Pobreza } \\
\text { Siervos } \\
\text { Criados } \\
\text { Mendigos } \\
\text { Efecto agradable } \\
\text { Equilibrio } \\
\text { Gravedad } \\
\text { Severidad } \\
\text { Confortable } \\
\text { Nobleza }\end{array}$ & $\begin{array}{l}\text { Nuevo } \\
\text { Color } \\
\text { Apetitosa } \\
\text { Rosa de amor } \\
\text { Deliciosamente } \\
\text { Adictiva } \\
\text { Cálida } \\
\text { Endulzada } \\
\text { Jugosa } \\
\text { Se divierte } \\
\text { Transportada } \\
\text { Ácidos } \\
\text { Frambuesa } \\
\text { Vibraciones } \\
\text { Madera } \\
\text { Voluptuosidad } \\
\text { Avainilladas } \\
\text { Rosa espontánea } \\
\text { Irresistible } \\
\text { Envuelve }\end{array}$ \\
\hline
\end{tabular}

Fuente: elaboración propia

\section{Análisis de los resultados}

\subsection{Análisis del caso 1. Trésor}

El color principal de la escena se corresponde con el del perfume. Se encuentran colores similares, aunque más desaturados, en los labios de la modelo. Este color principal es un tono anaranjado, similar al del ámbar. Las connotaciones de este color que se adecúan con el posicionamiento buscado son fuego superior, potente y magnífico, calor y acogedor, relacionadas directamente con el posicionamiento buscado por el anunciante: amor, tesoro, afrutadas, ambarinas, diseño precioso, mujer radiante, y preciosa. 
El color dominante es un marrón procedente del arco de los naranjas. El marrón tiene como atribuciones vestimenta, otoño, moda, naturaleza, efecto agradable, eguilibrio, gravedad, confortable y nobleza. Estos términos pueden relacionarse con notas florales, afrutadas, ambarinas, tesoro y mujer radiante.

No obstante se observa una tendencia hacia una tonalidad cálida anaranjada, con un recuerdo al color principal. Realmente es un naranja con una baja saturación y un alto grado de brillo. El dominante se establece como soporte en el que se desenvuelven el resto de colores presentes en la imagen, y refuerza la sensación de una atmósfera cálida.

El segundo color percibido tras el color principal es el negro. Sus connotaciones son juventud, moda, silencio, misterio, noche, nobleza y elegancia, que podemos relacionar con diseño precioso, ofrenda, mujer radiante.

De entre los colores más frecuentes, seis de ellos son colores desaturados y muy brillantes. En la gama de los tonos pastel.

El primero de ellos es el amarillo, con atribuciones de claridad, gratitud, armonía, ardiente y alegría. Es armonioso, luminoso y expansivo, y alegra el ánimo. En términos de percepción este color está muy presente en la imagen.

También se encuentra un rosa desaturado, casi blanco (con atribuciones de feminidad, suavidad, pasión, bien) aunque no es muy perceptible visualmente.

Tiene más presencia el blanco, que sirve de fondo a casi el cincuenta por ciento de la imagen. Favorece el contraste, y connota luminosidad, infinito, positivismo, paz, pureza, inocencia, perfección, el bien, y vida; con estos términos, apoya los conceptos de notas florales, empolvadas, mujer radiante, flota, aire y emoción.

El resto de los colores hacen referencia sobre todo a los marrones de la piel. Con distintos niveles de saturación (generalmente provenientes del naranja), configuran gradaciones distintas de los colores principal y dominante.

\subsection{Análisis del caso 2. Trésor in Love}

El color principal de la imagen es el rosa. Este color se encuentra en el frasco del perfume y en la piel de la chica. También aparece en los blancos del fondo y del vestido, aunque de una forma casi imperceptible. Las connotaciones de este color son: chicas jóvenes, feminidad, ternura erótica, desnudo, optimismo, pequeño, pudor, inocencia, suavidad, pasión, y bien. Podemos establecer relación con los términos empleados para el posicionamiento buscado del producto: instante precioso, comienza, ritmo lanzado, heroína, enternecedora, 
emociones, joven, mujer, enamorada, suavidad infinita, sentimientos, floral irresistible, rosa con carácter, jazmín luminoso y objeto de deseo. La luminosidad alta aporta vitalidad a la conceptualización del color.

El color dominante es un gris poco luminoso, proveniente del rojo (al igual que el rosa, que es un rojo poco saturado) y próximo al negro. Las atribuciones del gris equiparables a las del posicionamiento son neutralidad, experiencia y sabiduría. No encontramos analogías en este caso entre las connotaciones del color dominante y los valores buscados para el posicionamiento del producto. Sí observamos, por las características del color, su proximidad a la atmósfera de la escena.

El color más importante después del principal es el negro. Sus connotaciones son: juventud, moda, silencio, misterio, noche, nobleza, elegancia y credibilidad. Podemos relacionarlas con los conceptos de posicionamiento: joven, contrastes, rosa con carácter, objeto de deseo y moderna.

El siguiente es el blanco. Si bien los valores reales lo definirían como gris, perceptivamente se relaciona con su contrario (el negro) como un blanco. Sus valores son: desconocido, luminosidad, infinito, confiere positivismo, paz, pureza, inocencia, perfección, el bien y vida. Se establece analogía con: precioso, comienza, juega, melodía, espontaneidad, joven, suavidad infinita, jazmín luminoso, energía, y moderna.

El resto de los colores más presentes hacen referencia al negro en mayor medida, además de un gris.

\subsection{Análisis del caso 3. Trésor Midnight Rose}

El color principal de la imagen es el violeta. Sus connotaciones son: masculinidad y feminidad, sensualidad, espiritualidad, sexo, contradictorio, incitación exenta de alegría, lucidez. La significación buscada se encuentra en los siguientes términos que concuerdan con éstas connotaciones: rosa de medianoche, apetitosa, rosa de amor, deliciosamente, adictiva, cálida, endulzada, jugosa, se divierte, transportada, vibraciones, voluptuosidad, rosa espontánea, irresistible, y envuelve.

El color dominante es un violeta algo más brillante que el principal. Forma parte del fondo de la imagen y del perfume. También encontramos reflejos en el rostro de la modelo. Las connotaciones son las mismas que las del color principal, puesto que no hay modificación de matiz.

Podemos decir que, para la generación de la atmósfera de la imagen, intervienen el color principal y el dominante. 
De los colores más frecuentes, siete entran dentro de la denominación violeta, si bien observamos que existen valores que van desde los denominados lila, con una saturación menor y un brillo alto, con connotaciones de dispersión y desatención, a los llamados púrpura, muy saturados y menos luminosos, y con connotaciones bastante distintas: imperial, majestuoso, jerarquía. Éstos últimos se encuentran de forma muy señalada en la rosa que decora el perfume.

También juega un papel significativo el marrón, que se encuentra en los matices de la piel de la chica, y que tiene una ligera tendencia al naranja. Es un tono con una luminosidad alta y con un brillo medio. Las atribuciones semejantes son: vestimenta, otoño, moda, efecto agradable, confortable y nobleza, que concuerdan con cálida jugosa, frambuesa, madera, y avainilladas.

El negro está presente en una parte de la cabeza de la modelo, contrastando con la parte más clara, casi blanca. Connota juventud, moda, noche, silencio, misterio, nobleza, elegancia, credibilidad, y majestuoso. Podemos encontrar relación con los términos de posicionamiento: medianoche, nuevo, color, voluptuosidad, irresistible, envuelve, y midnight rose.

El rojo aparece en los labios de la modelo. Sus atribuciones de significado son: vitalidad, pasión, enamora, energía y exaltante. Encontramos relación con los términos utilizados por la marca: cálida, jugosa, se divierte, vibraciones, voluptuosidad, irresistible, y envuelve.

\section{Conclusiones}

1. El color es uno de los elementos que aporta significados connotados en la fotografía publicitaria. Al menos, así se ha puesto de manifiesto en los tres casos analizados en esta investigación. Hemos comprobado, de forma empírica, las afirmaciones vertidas en textos fundamentales sobre la materia, tales como: la Teoría de los Colores de Johann Wolfgang von Goethe, De lo espiritual en el arte de Vasili Kandinski, o, en un plano más contemporáneo, Costa (1992), Heller (2004), Ferrer (1999) y Subiela (2010).

2. Existen una serie de significados connotados que se han asociado de forma cultural a los distintos tonos y que han quedado reflejados en la literatura especializada. Estos significados, que podemos considerar muy extendidos para la cultura occidental, han sido recopilados y se ha elaborado con ellos una tabla sintética que recoje la relación color - significado connotado. 
3. La herramienta diseñada en esta investigación permite relacionar los connotadores del color con la intencionalidad de la imagen publicitaria. Para ello, hemos determinado, para cada imagen analizada, el color principal, el color dominante y los colores frecuentes y luego hemos enfrentado sus significados connotados con la intencionalidad del anunciante (plasmada en el posicionamiento perseguido para el producto anunciado).

La aplicación de esta herramienta al análisis de tres piezas publicitarias de perfumes de la compañía Lancôme nos ha permitido extraer otra serie de conclusiones de carácter más concreto, y que exponemos a continuación.

3.1. Existe una analogía entre los significados atribuidos al color principal de una fotografía publicitaria y los conceptos de posicionamiento empleados por el anunciante.

3.2. Los connotadores del color relacionados con los conceptos de posicionamiento empleados por el anunciante siempre son significados relacionados con los aspectos positivos de aquellos.

3.3. El color principal (que se corresponde con el color del producto) aparece en distintas zonas de la fotografía publicitaria con variaciones de saturación y brillo controladas para mantener la percepción del mismo.

3.4. El color dominante de una escena se emplea para conferir una atmósfera general que se utiliza como base para la construcción del resto de la imagen.

3.5. La relación tonal que se establece entre el sujeto principal de la fotografía y el fondo es de contraste.

3.6. El negro tiene presencia significativa en las imágenes estudiadas. En todos los casos tiene importancia en la distribución de la lectura, aportando significado a la fotografía. En aquellas partes de la imagen menos importantes en las que aparece, se emplea como modelador de las formas, favoreciendo el contraste y aumentando así el volumen. El blanco, además de las connotaciones atribuibles en los casos en las que se considera como un color frecuente, se emplea, como el negro, como elemento de contraste, aportando sensación de profundidad.

3.7. Los grises y los marrones, como colores con saturación baja o distintos niveles de brillo provenientes de tonos puros, mantienen matices de los colores saturados originales, aportando más valor del atribuible únicamente a un gris o a un marrón. Un tono puede ser percibido como gris, pero si cromáticamente tiene aportaciones de otro color, connotará también como ese color. 
Más allá de estas conclusiones de carácter general y específico, entendemos que la herramienta de recogida de datos y posterior análisis que se ha ideado para esta investigación es útil para el estudio de la connotación del color en la imagen, sea o no publicitaria.

\section{Bibliografía}

Abreu, C. (1999a). La opinión fotográfica. Información y opinión: binomio inseparable. Revista Latina de Comunicación Social (23), 6.

Abreu, C. (1999b). La opinión fotográfica (II). Recursos connotativos de la fotografía. Revista Latina de comunicación social (24), 9.

Abreu, C. (2000). La opinión fotográfica (y III). Revista Latina de comunicación social (26), 7.

Aparici, R., García Matilla, A. y Valdivia Santiago, M. (1992). La imagen. Madrid: UNED.

Aparici, R. García Matilla, A., Fernández Baena, J. y Osuna Acedo, S. (2009). La imagen. Análisis y representación de la realidad. Barcelona: Gedisa.

Asociación Nacional de Perfumería y Cosmética. (2012, 20-noviembre). bttp:/ / www.stanpa.com.

Aumont, J. (1992). La Imagen. Barcelona: Paidos.

Barthes, R. (1989). La cámara lúcida. Nota sobre la fotografía. Barcolena: Paidós comunicación.

Barthes, R. (2002). Lo obvio y lo obtuso. Barcelona: Ediciones Paidós Ibérica.

Barthes, R. (1993). Mitologias. Buenos Aires: Siglo XXI.

Colle, R. (1999). El contenido de los mensajes icónicos. Revista Latina de Comunicación Social.

Costa, J. (1992). "Los recursos combinatorios del grafismo funcional" en MOLES, Abraham y JANISZEWISKI, Luc. Grafismo funcional. Barcelona: CEAC.

Eco, H. (2000). Tratado de semiótica general. Barcelona: Lumen.

Eguizábal, R. (2005). El análisis de la imagen fotográfica. Actas del I Congreso Internacional de Teoría y Técnica de los Medios Audiovisuales. Universitat Jaume I, Castellón octubre 2004. In P. d. I (Ed.), La fotografía publicitaria (pp. 81-98). Castellón: Universitat Jaume I.

Eguizábal, R. (2001). Fotografía publicitaria. Madrid: Ediciones Cátedra.

Ferrer, E. (1999). Los Lenguajes del color. México.: Fondo de cultura económica.

Fontcuberta, J. (2003). Estética Fotográfica. Barcelona: Gustavo Gili.

Fontcuberta, J. (1984). Estética fotográfica: selección de textos. Barcelona: Blume.

Garrido Lora, M. (1995). El iconosimbolismo de la imagen publicitaria. En VV.AA., Algunas consideraciones sobre la comunicacion empresarial e institucional (pp. 73-80). Sevilla: MAECEI. 
Goethe, J. W. (1999). Teoría de los Colores. Valencia: Colegio oficial de arquitectos de Murcia.

Goldstein, E. B. (2006). Sensación y percepción. Madrid: Thomson.

González Solas, J. (2001). Los límites de la significación en la identidad visual corporativa. Área Abierta (1).

Gubern, R. (1974). Mensajes icónicos en la cultura de masas.

Heller, E. (2004). Psicología del Color. Barcelona: Gustavo Gili.

Hochberg, J. (1983). La representación de objetos y personas. En J. Hochberg, M. Black, y E. Gombrich, Arte, percepción y realidad. Barcelona: Paidós Comunicación.

Huygens, C. (1690). Traité de la lumière.

Joly, M. (2003). La imagen fija. Buenos Aires: Biblioteca de la mirada.

Küppers, H. (1995). Fundamentos de la teoría de los colores. Barcelona: Gustavo Gili. Lancôme España. www.lancomespain.com.

Marty, C., y Marty, R. (1995). La semiótica. 99 respuestas. Buenos Aires: Edicial.

Perea, J. (2000). Los géneros fotográficos. Universo Fotográfico (2), 61-81.

Präkel, D. (2007). Iluminación. Barcelona: Blume.

Rodríguez García, S. E. (2008). Connotación y persuasión en la imagen publicitaria. (U. d. Granada, Ed.) Gazeta de antropología (24 (2)), artículo 55.

Subiela Hernández, B. J. (2010). El diseño de revistas como lenguaje: fundamentos teóricos. Tesis doctoral. Murcia: Universidad Católica San Antonio de Murcia.

Susperregui, J. M. (2001). La linealidad de la luz: La comunicación visual moderna. ZER, Revista de estudios de comunicación (10), 177-193.

Universidad Jaume I de Castellón. (2012, 15-noviembre) http://www.analisisfotografia.uji.es/root2/intr.html Zorrilla, J. (2002). Introducción al diseño periodístico. Eunsa: Barañain.

Zunzunegui, S. (1998). Pensar la imagen. Madrid: Cátedra/Universidad del País Vasco 


\section{Notas}

2 Diecinueve universidades españolas se han unido en un proyecto I+D sobre competencia mediática, en el que también colabora el autor principal de esta investigación y a partir del cual surge el presente trabajo.

${ }^{3}$ www.analisisfotografia.uji.es consultada el 20 de noviembre de 2012

${ }^{4}$ Disponible de forma gratuita en la web www.whatsitscolor.com

${ }^{5}$ Kuler está disponible en www.kuler.adobe.com

\section{Currículum}

\section{Félix Galindo Marín}

Profesor ayudante licenciado

Departamento de Comunicación - Facultad de Ciencias Sociales y de la Comunicación, Universidad Católica San Antonio de Murcia, UCAM, Avenida de los Jerónimos, 135, 30107, Guadalupe (Murcia, España). Teléfonos: 968278963 - fax: 968278586

Correo electrónico: fgalindo@ucam.edu

Licenciado en Comunicación Audiovisual por la Universidad Católica de Murcia (UCAM) en el año 2001. Comienza su labor docente en el campo de la fotografía en la Consejería de Educación de Murcia en el ámbito de la formación profesional. Desde 2003 es docente e investigador de la UCAM, impartiendo materias relacionadas con la imagen y la tecnología educativa. Doctorando en Comunicación. Ha realizado trabajos de asesoría en el campo de la imagen para empresas de comunicación en la región de Murcia. Organiza y participa en actividades de difusión de la fotografía tanto en el ámbito académico como comunitario. Participa en el proyecto de investigación sobre Competencia Mediática Proyecto COMPECAV-PC Ref: EDU2010-21395-C03. Sus áreas de interés se centran en el estudio de la imagen y su significado, y en el uso de las tecnologías en la educación. Participa en publicaciones relacionadas con la tecnología educativa y educación y medios.

\section{Dr. Blas José Subiela Hernández}

Profesor ayudante doctor

Departamento de Comunicación - Facultad de Ciencias Sociales y de la Comunicación, Universidad Católica San Antonio de Murcia, UCAM, Avenida de los Jerónimos, 135, 30107, Guadalupe (Murcia, España). Teléfonos: 968278744 - fax: 968278586 Correo

electrónico:bsubiela@ucam.edu 
Licenciado en Publicidad y RR.PP en el CEU San Pablo de Valencia en el año 1998. Tras desarrollar varios trabajos profesionales en el sector del diseño y la comunicación (Expert, Visual Magazine, Aedico, Grupo Anuntis), desde el año 2004 es docente e investigador en la Universidad Católica San Antonio de Murcia (UCAM). Defiende su tesis doctoral, titulada "El diseño de revistas como lenguaje: fundamentos teóricos" con calificación de sobresaliente "cum laude" por unanimidad en la misma universidad en junio de 2010 y obtiene el título de doctor en comunicación. Forma parte del grupo de investigación "Publicidad y RR.PP. Redefiniciones, públicos y medios" del Departamento de Comunicación de la UCAM. Sus áreas de interés en el ámbito de la investigación giran en torno a la comunicación visual y la retórica de la imagen, con una especial atención a la tipografía y a la identidad visual corporativa. Ha participado en varios congresos de comunicación con ponencias específicas sobre diseño gráfico y comunicación. Y ha publicado artículos científicos en las revistas Icono 14 y Sphera Publica.

\section{Dr. Manuel González-Sicilia Llamas}

Profesor asociado

Departamento de Comunicación - Facultad de Ciencias Sociales y de la Comunicación, Universidad Católica San Antonio de Murcia, UCAM, Avenida de los Jerónimos, 135, 30107, Guadalupe (Murcia, España). Teléfonos: 968278963 - fax: 968278586

Correo electrónico:mgsicilia@ucam.edu

Profesor de la UCAM, Universidad Católica de Murcia, desde hace dieciseis años, en donde imparte las asignaturas Marketing Aplicado a la Comunicación e Historia del Cine. Licenciado en Filosofía y Letras y Doctor en Padagogía por la Universidad de Murcia. Autor de diversas publicaciones en España y América Latina, ha impartido cursos en una docena de universidades tanto españolas como iberoamericanas. Ha pertenecido a numerosos Comités Científicos de Congresos Internacionales relacionados con la Educación, los Medios Audiovisuales y las TIC, y es miembro de EDUTEC y de la Red Iberoamericana para el Desarrollo de Aplicaciones Telemáticas en la Formación Universitaria. Ha desarrollado una intensa carrera profesional en diversos puestos de responsabilidad en las áreas de Comunicación y Marketing, en la empresa privada, durante más de 35 años. 


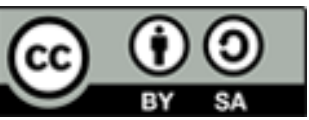

Licencia Creative Commons

Miguel Hernández Communication Journal

mhcj.es

\section{Forma de citar este artículo en las bibliografías}

Félix Galindo Marín, Blas José Subiela Hernández y Manuel González-Sicilia Llamas (2014):

“Análisis del color como connotador en la fotografía publicitaria”, en Miguel Hernández Communication Journal, nº5, páginas 53 a 90. Universidad Miguel Hernández, UMH (ElcheAlicante). Recuperado el __ de de $20 \ldots$ de:

http: $/ /$ mhcj.es $/$ index.php?journal $=$ mhcj\&page $=$ article\&op $=$ view\&path $\% 5 \mathrm{~B} \% 5 \mathrm{D}=55$ 